\title{
Preparation of three-dimensionally ordered macroporous perovskite materials
}

\author{
FANG JunFei, XUAN YiMin* \& LI Qiang \\ School of Power Engineering, Nanjing University of Science \& Technology, Nanjing 210094, China
}

Received February 22, 2011; accepted April 13, 2011

\begin{abstract}
In this paper, we use $\mathrm{La}_{0.8} \mathrm{Sr}_{0.2} \mathrm{MnO}_{3}$ and $\mathrm{La}_{0.7} \mathrm{Ca}_{0.2} \mathrm{Sr}_{0.1} \mathrm{MnO}_{3}$ as examples to demonstrate a preparation method for threedimensionally ordered macroporous (3DOM) perovskite thermochromic materials. Polystyrene spheres with an average diameter of $220 \mathrm{~nm}$ were self-assembled into a three-dimensionally ordered colloidal crystal template. A mixed metal nitrate solution prepared using $\mathrm{La}\left(\mathrm{NO}_{3}\right)_{3} \cdot 6 \mathrm{H}_{2} \mathrm{O}, \mathrm{Ca}\left(\mathrm{NO}_{3}\right)_{2} \cdot 4 \mathrm{H}_{2} \mathrm{O}, \mathrm{Sr}\left(\mathrm{NO}_{3}\right)_{2}, \mathrm{Mn}\left(\mathrm{CH}_{3} \mathrm{COO}\right)_{2} \cdot 4 \mathrm{H}_{2} \mathrm{O}$ and an ethanol precursor was used to fill the interstitial voids of the polystyrene colloidal crystal templates. $3 \mathrm{DOM} \mathrm{La}{ }_{0.8} \mathrm{Sr}_{0.2} \mathrm{MnO}_{3}$ and $\mathrm{La}_{0.7} \mathrm{Ca}_{0.2} \mathrm{Sr}_{0.1} \mathrm{MnO}_{3}$ materials were then obtained after the sphere templates were removed via drying and calcination. The results show that the framework of the 3DOM materials can have different thicknesses and pore shrinkage rates by varying the filling times. In addition, the Curie temperatures of the $3 \mathrm{DOM}$ and bulk $\mathrm{La}_{0.8} \mathrm{Sr}_{0.2} \mathrm{MnO}_{3}$ materials can be varied by altering the preparation method.
\end{abstract}

polystyrene spheres, colloidal crystal template, 3DOM, perovskite-type materials, thermochromic materials

Citation: $\quad$ Fang J F, Xuan Y M, Li Q. Preparation of three-dimensionally ordered macroporous perovskite materials. Chinese Sci Bull, 2011, 56: 2156-2161, doi: $10.1007 / \mathrm{s} 11434-011-4531-\mathrm{y}$

Three-dimensionally ordered macroporous (3DOM) materials have a three-dimensional strictly periodic spatial network structure with submicron pore sizes [1-3]. Because of their unique structural characteristics 3DOM materials have a wide spectrum of applications, including catalyst supports [4-6], filtration and separation [3,7], battery materials [8,9], and sensors $[10,11]$. The periodicity of the spatial arrangement of the 3DOM materials can control the propagation of visible light and near-infrared light. Consequently, 3DOM materials also have important applications in the fabrication of photonic crystals and various other optical and optoelectronic devices [2,6,12,13].

Currently, 3DOM materials are prepared primarily using the colloidal crystal template method $[1,3,4,6]$. These methods are based on templates including monodispersed polystyrene (PS), polymethyl methacrylate (PMMA), and $\mathrm{SiO}_{2}$ colloidal spheres. These templates can be assembled into colloidal crystals using gravitational sedimentation,

*Corresponding author (email: ymxuan@mail.njust.edu.cn) centrifugal sedimentation, or vertical deposition. Then, the precursor solution is used to fill the interstitial regions of the colloidal crystal template. After subsequent transformation in the colloidal crystals, the template is removed via roasting or dissolving. Through this process, 3DOM materials with different components materials can be obtained.

Perovskite oxide materials such as perovskite manganite are generally used as thermal radiation surface materials because of their thermochromic properties [14-16]. Research has shown that for a temperature change from 173 to $373 \mathrm{~K}$, the emissivity of the perovskite manganese oxide changes drastically [14-16]. Intelligent thermal control components can be made using thermochromic materials by bonding such a material to the surface of a temperature control device. The material will adjust its radiation characteristics according to the temperature of the equipment. Thus, intelligent control of the device temperature can be achieved by controlling the radiation energy exchange between the equipment and its external environment. Previous studies have only changed the material properties to study the radi- 
ation characteristics of the functional thermochromic surface $[16,17]$. In fact, changes in the surface microstructure of thermochromic functional materials will lead to changes in surface radiation properties. Therefore, it is feasible that, if thermochromic functional materials are made using 3DOM structures, changes in temperature can both change and regulate the surface radiation properties. Therefore, the study of the coupling effects between temperature and surface microstructures in thermochromic functional materials is of great importance. However, there have not yet been reports on research in this area.

In this paper, the preparation of ordered PS colloidal crystal templates via the self-assembly method is presented. Then, a mixed metal nitrate solution prepared using $\mathrm{La}\left(\mathrm{NO}_{3}\right)_{3} \cdot 6 \mathrm{H}_{2} \mathrm{O}$, $\mathrm{Ca}\left(\mathrm{NO}_{3}\right)_{2} \cdot 4 \mathrm{H}_{2} \mathrm{O}, \mathrm{Sr}\left(\mathrm{NO}_{3}\right)_{2}, \mathrm{Mn}\left(\mathrm{CH}_{3} \mathrm{COO}\right)_{2} \cdot 4 \mathrm{H}_{2} \mathrm{O}$ and an ethanol precursor is used to fill in the interstitial regions of the PS colloidal crystal template. The process results in 3DOM $\mathrm{La}_{0.8} \mathrm{Sr}_{0.2} \mathrm{MnO}_{3}$ and $\mathrm{La}_{0.7} \mathrm{Ca}_{0.2} \mathrm{Sr}_{0.1} \mathrm{MnO}_{3}$ materials after the PS colloidal crystal template was removed by drying and calcining. Thereby, we establish a method of preparation for 3DOM perovskite thermochromic materials. Changes in the surface microstructure of this intelligent material, perovskite manganite, lead to changes in its surface radiation characteristics. This is of great importance for research on surface radiation characteristics of perovskite manganite thermochromic functional materials and their applications.

\section{Experimental}

\subsection{Synthesis of PS colloidal spheres}

The PS colloidal spheres were synthesized via the emulsion polymerization method $[18,19]$. The PS colloidal spheres had an average diameter of $220 \mathrm{~nm}$. This was achieved by carefully controlling the synthesis conditions. The resulting PS spheres are monodispersed to a high degree. This allows for easy assembly of the PS sphere ordered colloidal crystal template.

\subsection{Assembly of polystyrene (PS) colloidal crystal tem- plate}

In our experiment, the PS colloidal spheres were assembled into a three-dimensional ordered colloidal crystal template via vertical deposition [20,21] and dip-drawing [9,22]. The specifics of the process of vertical deposition are as follows. First, the mother liquor of the PS spheres was diluted with deionized water to a concentration of about $1 \%$ and ultrasonicated. Then, a clean dry quartz glass substrate was vertically inserted into a weighing bottle containing the PS colloidal solution. Then, the bottle was immediately placed in an oven at $40^{\circ} \mathrm{C}$ and $60 \%$ relative humidity for $2 \mathrm{~d}$. After that, a multicolored colloidal crystal film with an area of 20 $\mathrm{mm} \times 10 \mathrm{~mm}$ was obtained on the quartz glass. The sample was taken out and dried at room temperature for $1 \mathrm{~d}$. The resulting colloidal crystal was sintered at $70^{\circ} \mathrm{C}$ in an oven for $1 \mathrm{~h}$ to enhance the strength and connectivity between the spheres. Then, it was cooled to ambient temperature for further use as a template.

The steps of the dip-drawing method are as follows. First, the mother liquor of the PS spheres was diluted with deionized water to a concentration of about $10 \%$ and ultrasonicated. Then, a quartz glass substrate was vertically inserted into a stable beaker containing the PS colloidal solution. It was held in this position for a few minutes. Then, the glass substrate was drawn upward vertically at a speed of 2 $\mathrm{mm} / \mathrm{min}$. After the glass substrate was completely removed from the solution, the sample was dried at room temperature for $1 \mathrm{~d}$. To enhance the strength of the PS colloidal crystal, the same heat treatment as that of the above vertical disposition process was applied. Through this process, the ordered PS colloidal crystal template was obtained.

\subsection{Fabrication of the 3DOM composite metal oxide}

Ethanol was chosen as the solvent. The precursor solution was prepared using metal nitrate in the proportion $\mathrm{La}\left(\mathrm{NO}_{3}\right)_{3} \cdot 6 \mathrm{H}_{2} \mathrm{O}: \mathrm{Sr}\left(\mathrm{NO}_{3}\right)_{2}: \mathrm{Mn}\left(\mathrm{CH}_{3} \mathrm{COO}\right)_{2} \cdot 4 \mathrm{H}_{2} \mathrm{O}=0.8: 0.2: 1$. Then, it was stirred several hours until all the materials were completely dissolved. After the PS colloidal crystal template was immersed in the precursor solution for a few minutes, the sample was drawn upward vertically at a speed of $2 \mathrm{~cm} / \mathrm{min}$. Then, it was immediately placed in a drying oven for $1 \mathrm{~h}$. This process was repeated once, which ensured that the colloidal crystal template was completely infiltrated. The sample was stored at room temperature overnight and then placed in a tube furnace. The temperature of the oven increased at a rate of $1{ }^{\circ} \mathrm{C} / \mathrm{min}$ via slowly injected air. Then, the temperature was held at $350^{\circ} \mathrm{C}$ for 2 $\mathrm{h}$ to remove the colloidal crystal template. Then it was heated to $600^{\circ} \mathrm{C}$ and held there for $3 \mathrm{~h}$. Later, it was cooled to ambient temperature. Through this process, the 3DOM $\mathrm{La}_{0.8} \mathrm{Sr}_{0.2} \mathrm{MnO}_{3}$ composite metal oxide material was obtained.

Another 3DOM sample was prepared using a solution of proportion, $\mathrm{La}\left(\mathrm{NO}_{3}\right)_{3} \cdot 6 \mathrm{H}_{2} \mathrm{O}: \mathrm{Ca}\left(\mathrm{NO}_{3}\right)_{2} \cdot 4 \mathrm{H}_{2} \mathrm{O}: \mathrm{Sr}\left(\mathrm{NO}_{3}\right)_{2}: \mathrm{Mn}$ $\left(\mathrm{CH}_{3} \mathrm{COO}\right)_{2} \cdot 4 \mathrm{H}_{2} \mathrm{O}=0.7: 0.2: 0.1: 1$. The PS colloidal crystal template was only filled and dried once. However, all the other processes were the same as above. Also, a 3DOM sample using $\mathrm{La}_{0.7} \mathrm{Ca}_{0.2} \mathrm{Sr}_{0.1} \mathrm{MnO}_{3}$ oxide was prepared.

\subsection{Preparation of bulk $\mathrm{La}_{0.8} \mathrm{Sr}_{0.2} \mathrm{MnO}_{3}$}

Bulk $\mathrm{La}_{0.8} \mathrm{Sr}_{0.2} \mathrm{MnO}_{3}$ of the same composition was prepared via the conventional solid-state reaction method [17]. The process was as follows. First, $\mathrm{La}_{2} \mathrm{O}_{3}, \mathrm{SrCO}_{3}$ and $\mathrm{MnO}_{2}$ (all raw materials were of $99.99 \%$ purity and pretreated by heating) were weighed according to the above-mentioned proportions. They were then immediately placed in a ball 
mill for grinding. Then, the mixture was placed in a muffle furnace for calcination at $1473 \mathrm{~K}$ for $36 \mathrm{~h}$. The calcined powder was re-ground in the ball mill and then pressed into a wafer. The sample was sintered again and then furnace-cooled to room temperature. Finally, the sample was machined into a disc.

\subsection{Characterization of the PS colloid crystal template and the 3DOM and bulk materials}

The surface morphologies of the PS colloidal crystal templates and the 3DOM oxide materials were characterized using a S-4800 field-emission scanning electron microscope (SEM) (Hitachi, Tokyo, Japan) with an acceleration voltage of $15 \mathrm{kV}$. Gold sputtering processing was carried out on the sample surface prior to observation. The transmittance spectra of the PS colloidal crystal templates were recorded using a U-3400 UV/Vis/NIR spectrophotometer (Hitachi, Tokyo, Japan). Powder X-ray diffraction (XRD) patterns for the $3 \mathrm{DOM}$ and bulk $\mathrm{La}_{0.8} \mathrm{Sr}_{0.2} \mathrm{MnO}_{3}$ composite metal oxides were collected using a D8 super speed diffractometer (Bruker AXS, Karlsruhe, Germany). The Curie temperatures of the $3 \mathrm{DOM}$ and bulk $\mathrm{La}_{0.8} \mathrm{Sr}_{0.2} \mathrm{MnO}_{3}$ materials were determined using a Pyris 1 thermogravimetric analyzer (TGA) (Perkin-Elmer, Waltham, MA, USA).

\section{Results and discussion}

\subsection{Morphology and transmittance spectra analysis of the PS colloidal crystal templates}

SEM images of the PS colloidal crystal templates are shown in Figure 1. The diameter of the PS spheres is about $220 \mathrm{~nm}$. In one plane, each sphere is tightly surrounded by 6 spheres, which forms a hexagonal array structure in the colloidal crystal. Theoretical analysis indicates that the hexagonal array structure is thermodynamically stable [23]. It can be seen from the point defect in Figure 1(a) that the colloidal crystal is basically a face-centered cubic (fcc) close-packed structure. The surface shown is its (111) crystal plane.

As shown in Figure 1(a) and (b), there are more point defects and line defects in the colloidal crystal template prepared via dip-drawing than that prepared via vertical deposition. This is probably because the colloidal solution did not reach temperature equilibrium with the external environment during the dip-drawing process. In preparing a colloidal crystal template via dip-drawing, when the glass substrate is drawn out of the solution, the transformation of the PS spheres from disordered to ordered states is still ongoing. When the external environment temperature changes, it will affect the transformation of the PS spheres. Therefore, there will be more defects in the resulting colloidal crystal. In our experiment, the colloidal crystal prepared via vertical deposition was chosen as the template and filled with mixed
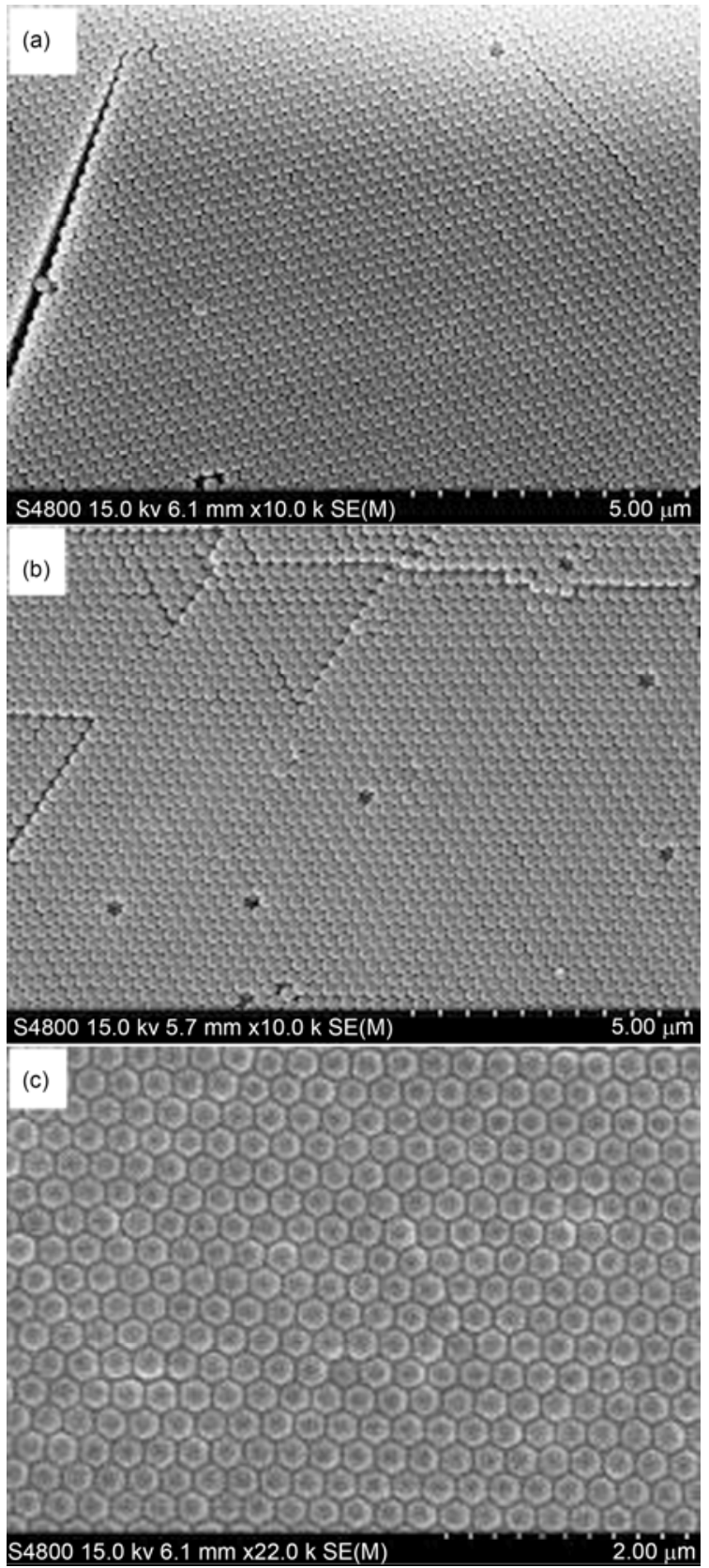

Figure 1 SEM images of the PS colloidal crystal templates prepared via vertical deposition (a), dip-drawing (b), or filled with a mixed metal nitrate solution (c).

metal nitrate solution. Then 3DOM perovskite metal oxides were prepared after drying and calcination.

Figure 2 shows the transmission spectrum curves of the PS colloidal crystal templates collected using a UV/Vis/NIR spectrophotometer. From Figure 2, it can be seen that a diffraction peak emerges at a wavelength of about $625 \mathrm{~nm}$ in both the curves. This suggests that the colloidal crystal templates prepared are highly ordered over a large (millimeter) range $[9,11]$. In addition, the diffraction peak of the colloidal crystal template prepared via vertical deposition method is closer to zero than that of the dip-drawn sample. 


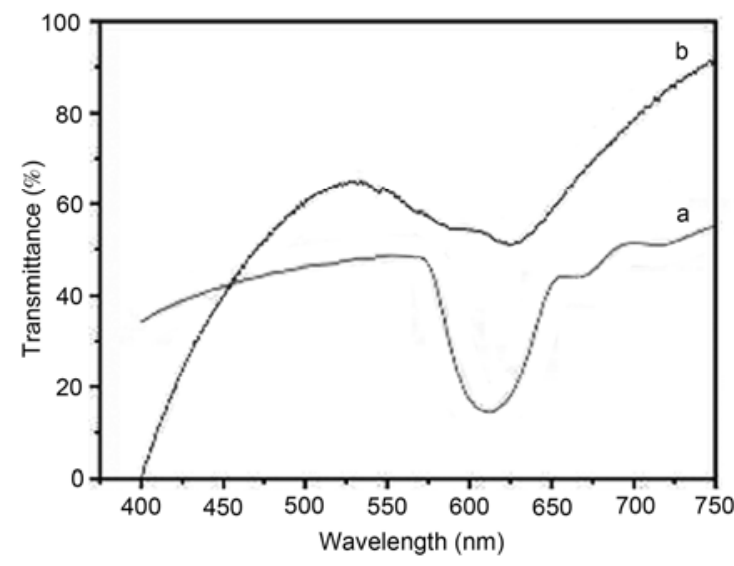

Figure 2 Transmission spectra of the PS colloidal crystal templates prepared via vertical deposition (a) and dip-drawing (b).

This indicates that the photonic bandgap features will be more clearly defined in this colloidal crystal. There are more cracks and point defects in the colloidal crystal template prepared via dip-drawing, which leads to the comparatively weak photonic band gap features in this colloidal crystal. Therefore, through analysis of the transmission spectra of the colloidal crystal templates, we can further show that the ordering of the template prepared via vertical deposition is better than that prepared via dip-drawing.

\subsection{Morphology analysis of $3 D O M \mathrm{La}_{0.8} \mathrm{Sr}_{0.2} \mathrm{MnO}_{3}$}

Figure 3 shows SEM images of the $3 \mathrm{DOM} \mathrm{La}_{0.8} \mathrm{Sr}_{0.2} \mathrm{MnO}_{3}$ material. From these images, it can be seen that the surface microstructure of the 3DOM material is highly ordered, and the pore distribution is highly uniform. The interstitial areas of the PS colloidal crystal templates were occupied by the skeletal structure of the 3DOM material. The areas originally occupied by the spheres have become voids. Therefore, the 3DOM material is a complete inverse of the PS colloidal crystal template. The pore diameter of the 3DOM materials is about $160 \mathrm{~nm}$, and the pore shrinkage rate is about $27 \%$ (compared with the original sphere size). This is because of the contraction effects between the template and the gel when they were filled and baked [6]. In addition, the high shrinkage of the pore could indicate the template was filled. In Figure 3(b), it can be seen that the major pores are interconnected by the smaller pores in regular arrays, forming a three-dimensional ordered network structure.

\subsection{XRD analysis of $3 D O M$ and bulk $\mathrm{La}_{0.8} \mathrm{Sr}_{0.2} \mathrm{MnO}_{3}$}

The XRD patterns for the 3DOM and bulk $\mathrm{La}_{0.8} \mathrm{Sr}_{0.2} \mathrm{MnO}_{3}$ materials are shown in Figure 4. From these XRD patterns, it can be seen that a strong diffraction peak emerges at $2 \theta$ $=32^{\circ}$, which is a characteristic peak of the perovskite crystal plane (110). In contrast to the standard XRD patterns for $\mathrm{La}_{0.8} \mathrm{Sr}_{0.2} \mathrm{MnO}_{3}$ perovskite materials, we conclude that the
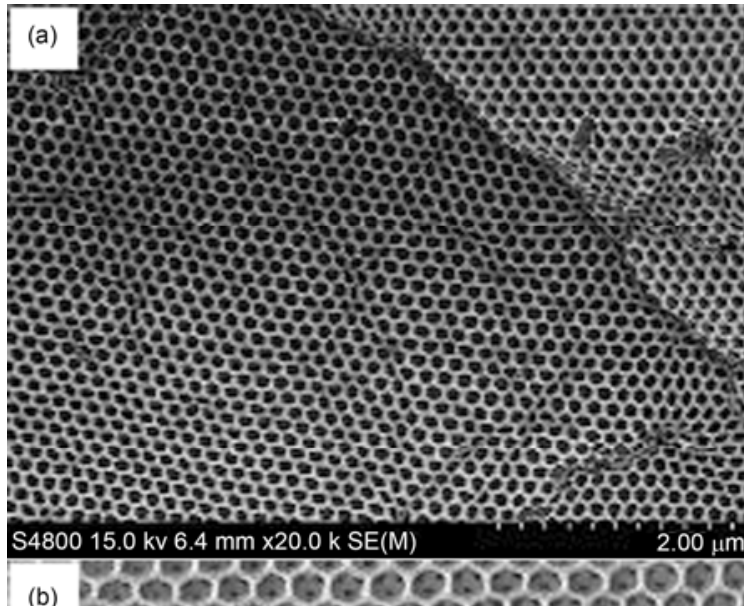

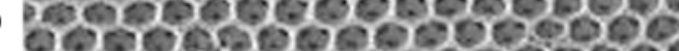

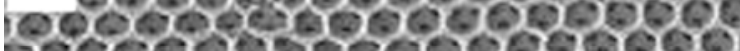

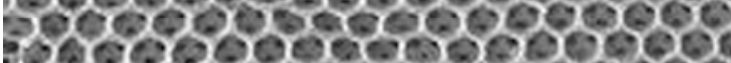

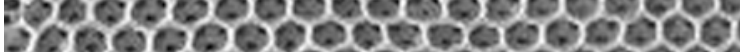

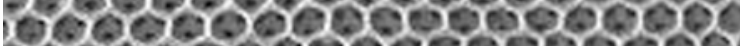

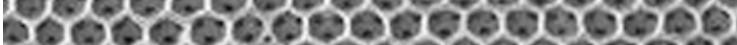

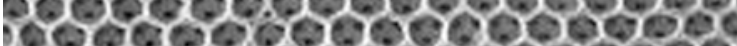

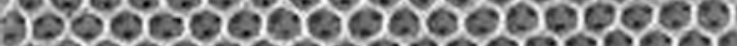

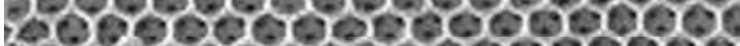

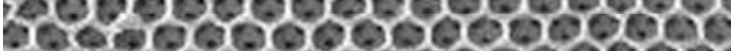

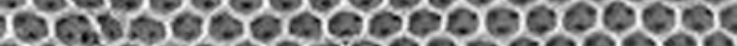

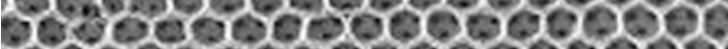

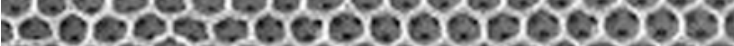

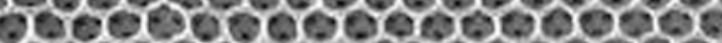
$\mathrm{S} 480015.0 \mathrm{kv} 6.0 \mathrm{~mm} \times 40.0 \mathrm{k} \mathrm{SE}(\mathrm{M}) \mathrm{m}$

Figure 3 SEM images of the $3 \mathrm{DOM} \mathrm{La}_{0.8} \mathrm{Sr}_{0.2} \mathrm{MnO}_{3}$ material.

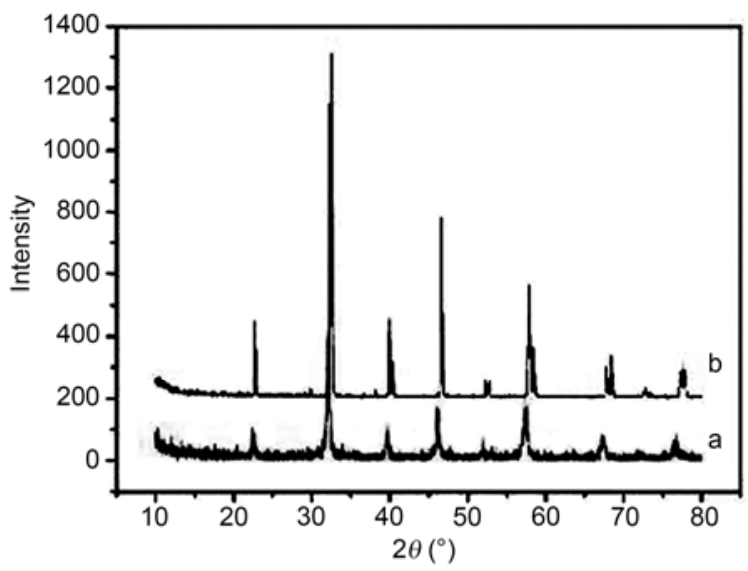

Figure 4 XRD patterns for the $3 \mathrm{DOM}$ (a) and bulk (b) $\mathrm{La}_{0.8} \mathrm{Sr}_{0.2} \mathrm{MnO}_{3}$ materials.

composite metal oxides prepared both have a primarily perovskite structure.

\subsection{Curie temperatures of $3 \mathrm{DOM}$ and bulk $\mathrm{La}_{0.8} \mathrm{Sr}_{0.2}$ $\mathrm{MnO}_{3}$}

Figure 5 shows the Curie temperature curves of the 3DOM and bulk $\mathrm{La}_{0.8} \mathrm{Sr}_{0.2} \mathrm{MnO}_{3}$ materials measured using a TGA. The vertical axis shows the equivalent weights of the 


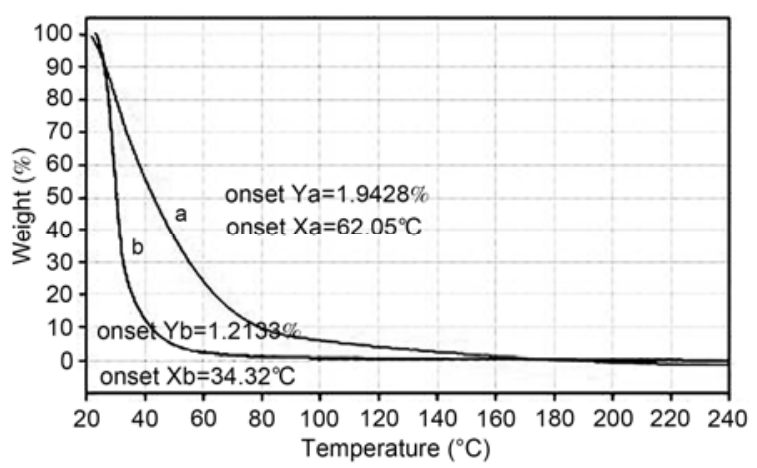

Figure 5 Curie temperature curves for the 3DOM (a) and bulk (b) $\mathrm{La}_{0.8} \mathrm{Sr}_{0.2} \mathrm{MnO}_{3}$ materials.

3DOM material under an external magnetic field rather than the actual weight. From the chart, it can be seen that the Curie temperatures of the $3 \mathrm{DOM}$ and bulk materials are about $62.05^{\circ} \mathrm{C}$ and $34.32^{\circ} \mathrm{C}$. The difference arises because of their different preparation methods. Moreover, their $\mathrm{Cu}$ rie temperatures are quite different. Near the Curie temperature, the perovskite oxide material properties will change from a ferromagnetic metallic state to a paramagnetic insulating state. As the temperature changes, the optical, electrical, magnetic $[14,16]$, and surface radiation characteristics will also change. By changing the surface microstructure and composition of the perovskite oxides, the Curie temperature can be set to be in the room temperature range. This could be important for intelligent thermal control processes based on this thermochromic material.

\subsection{Morphology analysis of 3DOM $\mathrm{La}_{0.7} \mathrm{Ca}_{0.2} \mathrm{Sr}_{0.1} \mathrm{MnO}_{3}$}

To verify the feasibility of preparing 3DOM perovskite thermochromic materials via the colloidal crystal template method, a 3DOM La $\mathrm{La}_{0.7} \mathrm{Ca}_{0.2} \mathrm{Sr}_{0.1} \mathrm{MnO}_{3}$ complex oxide was successfully prepared using the same method. The SEM images of the $3 \mathrm{DOM} \mathrm{La}_{0.7} \mathrm{Ca}_{0.2} \mathrm{Sr}_{0.1} \mathrm{MnO}_{3}$ film are shown in Figure 6. The pore diameter of the $3 \mathrm{DOM} \mathrm{La}_{0.7} \mathrm{Ca}_{0.2} \mathrm{Sr}_{0.1}$ $\mathrm{MnO}_{3}$ material is about $200 \mathrm{~nm}$, which corresponds to a pore shrinkage rate of about $9 \%$. In contrast to other $\mathrm{La}_{0.8} \mathrm{Sr}_{0.2} \mathrm{MnO}_{3}$ materials, as the filling time was reduced, the pore shrinkage rate of $\mathrm{La}_{0.7} \mathrm{Ca}_{0.2} \mathrm{Sr}_{0.1} \mathrm{MnO}_{3}$ material was significantly reduced. However, the 3DOM skeleton also became thinner.

\section{Conclusions}

In this paper, a preparation method for 3DOM perovskite thermochromic materials was presented. First, high-quality ordered PS colloidal crystal templates were prepared via vertical deposition and dip-drawing. Then, a mixed metal nitrate precursor solution was prepared using ethanol as a solvent. The solution was used to fill the interstitial regions of the PS colloidal crystal templates. After the sphere tem-
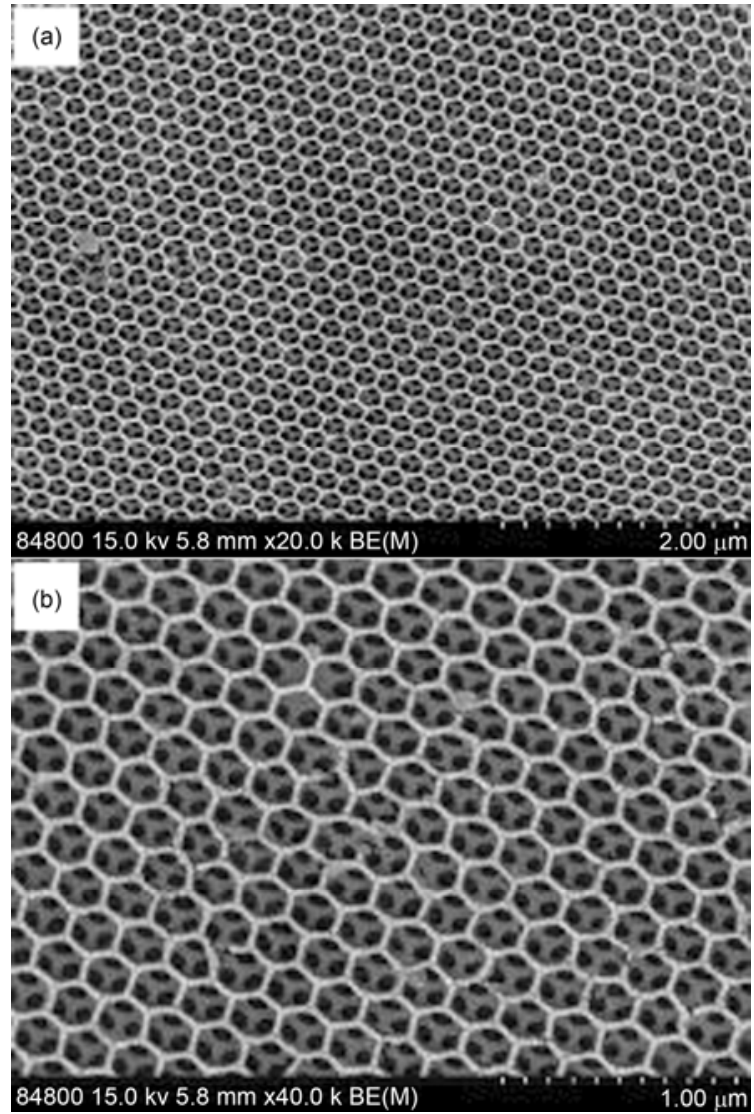

Figure 6 SEM images of the $3 \mathrm{DOM} \mathrm{La}_{0.7} \mathrm{Ca}_{0.2} \mathrm{Sr}_{0.1} \mathrm{MnO}_{3}$ material.

plates were removed via drying and calcination, 3DOM perovskite thermochromic materials of uniform pore sizes were obtained. The pore size and the pore size shrinkage can be adjusted by varying the filling time. The Curie temperatures of the $3 \mathrm{DOM}$ and bulk $\mathrm{La}_{0.8} \mathrm{Sr}_{0.2} \mathrm{MnO}_{3}$ materials are $62.05^{\circ} \mathrm{C}$ and $34.32^{\circ} \mathrm{C}$. These were determined using a TGA. Because of their differing preparation methods, their Curie temperatures are different. By changing the surface microstructure of the perovskite manganite material, the surface radiation characteristics can be changed. If the component ratio of the perovskite manganese oxides is adjusted, the phase transition temperature of the materials can be set to be in the room temperature range. This has a great significance for intelligent thermal control processes based on functional thermochromic materials.

1 Velev O D, Jede T A, Lobo R F, et al. Porous silica via colloidal crystallization. Nature, 1997, 389: 447-448

2 Yin Q, Liao J F, Wang C T, et al. Preparation, characterization and catalytic activity of three-dimensionally ordered macroporous $\mathrm{H}_{3} \mathrm{PW}_{12} \mathrm{O}_{40}-\mathrm{SiO}_{2}$ functionalized materials. Acta Chim Sin, 2007, 65: 2103-2108

3 Song C X, Yang L X, Chen X M, et al. Preparation of three-dimensionally ordered macroporous spinel $\mathrm{LiMn}_{2} \mathrm{O}_{4}$ by colloidal crystal template and its characterization. Chem J Chin Univ, 2007, 28: 204-207

4 Sadakane M, Asanuma T, Kubo J, et al. Facile procedure to prepare three-dimensionally ordered macroporous (3DOM) perovskite-type 
mixed metal oxides by colloidal crystal templating method. Chem Mater, 2005, 17: 3546-3551

5 Ren T Z, Yuan Z Y, Su B L. A novel macroporous structure of mesoporous titanias: Synthesis and characterization. Colloid Surf A: Physicochem Eng Asp, 2004, 241: 67-73

6 Yang W Y, Zheng J T. Synthesis of three-dimensionally ordered macroporous $\mathrm{SiO}_{2}$ by colloidal crystal template method. Chem Ind Eng Prog, 2006, 25: 1324-1327

7 Lee W, Braun P V. Epitaxially grown colloidal crystals of silica microspheres on patterned substrate of triangular arrays. Mater Sci Eng C, 2007, 27: 961-967

8 Matsushita S, Fujiwara R, Shimomura M. Calculation of photonic energy bands of self-assembled-type $\mathrm{TiO}_{2}$ photonic crystals as dye-sensitized solar battery. Colloid Surf A: Physicochem Eng Asp, 2008, 313: 617-620

9 Li W, Jin Z G, Liu Z F, et al. Preparation of polystyrene spheres (PS) templates and ordered porous $\mathrm{ZnO}$ films by dip-coating. J Inorg Mater, 2006, 21: 473-480

10 Li J L, Zhao X W, Wei H M, et al. Macroporous ordered titanium dioxide $\left(\mathrm{TiO}_{2}\right)$ inverse opal as a new label-free immunosensor. Anal Chim Acta, 2008, 625: 63-69

11 Kuo C Y, Lu S Y, Chen S F, et al. Stop band shift based chemical sensing with three-dimensional opal and inverse opal structures. Sensor Actuat B-Chem, 2007, 124: 452-458

12 Xu X S, Zhang D Z. The research and progress of micro-fabrication technologies of two-dimensional photonic crystal. Chinese Sci Bull, 2007, 52: 865-876

13 Abramova V, Sinitskii A. Large-scale $\mathrm{ZnO}$ inverse opal films fabricated by a sol-gel technique. Superlattice Microst, 2009, 45: 624-629
14 Shimazaki K, Ohnishi A, Nagasaka Y. Development of spectral selective multilayer film for a variable emittance device and its radiation. Int J Thermophys, 2003, 24: 757-769

15 Tang G C, Yu Y, Cao Y Z, et al. The thermochromic properties of $\mathrm{La}_{1-X} \mathrm{Sr}_{X} \mathrm{MnO}_{3}$ compounds. Sol Energ Mat Sol C, 2008, 92: 1298-1301

16 Wang J B, Xu M, Qiu J W. Applications of perovskite-structured manganese oxide in thermal control films. Chin J Vac Sci Technol, 2006, 26: 154-158

17 Li Q, Kuang L, Xuan Y M. Prepared method and radiative properties of a thermochromic variable emittance material. J Eng Thermophys, 2009, 30: 1005-1008

18 Li X W, Yan C H, Zhou C D, et al. Emulsifier-free emulsion copolymerization of styrene with sodium styrenesuifonate. Funct Polym, 1989, 2: 267-274

19 Li S, Zheng J T, Yang W Y, et al. A new synthesis process and characterization of three-dimensionally ordered macroporous $\mathrm{ZrO}_{2}$. Mater Lett, 2007, 61: 4784-4786

20 Wang J, Yuan C W, Huang Z B, et al. Synthesis and optical properties of durable opal photonic crystals with high crystalline quality. Acta Phys Sin, 2004, 53: 3054-3058

21 Zheng Z Y, Gao K Y, Luo Y H, et al. Rapidly infrared-assisted cooperatively self-assembled highly ordered multiscale porous materials. J Am Chem Soc, 2008, 130: 9785-9789

22 Takeda S, Wiltzius P. Growth of highly ordered colloidal crystals using self-assembly at liquid-liquid interfaces. Chem Mater, 2006, 18: 5643-5645

23 Cong H L, Cao W X. Two array manners and packing modes in colloidal crystals. Chem J Chin Univ, 2003, 24: 1489-1491

Open Access This article is distributed under the terms of the Creative Commons Attribution License which permits any use, distribution, and reproduction in any medium, provided the original author(s) and source are credited. 